\title{
PAPERS
}

\section{Exogenous nitric oxide inhibits apoptosis in guinea pig gastric mucous cells}

\author{
C L Potter, P J Hanson
}

\begin{abstract}
Background-Increased nitric oxide (NO) synthase activity and enhanced apoptosis are features of gastric mucosa infected with Helicobacter pylori and a causative relation has been suggested. However, although NO can promote apoptosis, its actions vary with cell type.

Aims-To determine whether exogenous NO, derived from an NO donor, might promote or counteract apoptosis in gastric mucous epithelial cells.

Methods-Primary cultures of guinea pig gastric mucosal cells were exposed to the NO donor S-nitroso-N-acetyl-penicillamine (SNAP) for 24 hours. Apoptosis was detected from nuclear staining with Hoechst 33258, in situ nick end labelling of DNA, and the presence of DNA "ladders" in cell extracts. Cyclic GMP content and caspase activity were determined by immunoassay and fluorimetric assay respectively.
\end{abstract}

Results-SNAP $1 \mathrm{mM}$ did not alter the small proportion of cells on the culture plate (3-6\%) which exhibited features of apoptosis. However, SNAP produced an inhibition of apoptosis, and of caspase 3 like activity, when enhanced by $25 \mu \mathrm{MN}$-hexanoyl-D-sphingosine $\left(\mathrm{C}_{6}\right.$-ceramide $)$, or by detachment of cells from the culture plate. The guanylate cyclase inhibitor, 1H-1, 2, 4-oxadiazole-4, 3-a-quinoxaline-1one (ODQ), prevented the stimulation of cyclic GMP by SNAP, but not the antiapoptotic effects of the NO donor. The cyclic GMP analogues 8-bromo-cyclic GMP and 8-(4-chlorophenylthio) guanosine-3',5'- cyclic monophosphate did not significantly inhibit apoptosis in the mucosal cells.

Pharmaceutical Sciences Institute, Aston University, Aston Triangle, Birmingham B4 7ET, UK

C L Potter

P J Hanson

Correspondence to: Dr P J Hanson.

Accepted for publication 9 September 1999
Conclusions-Exogenous NO inhibited apoptosis in guinea pig gastric mucous cells by a mechanism which did not involve elevation of cyclic GMP. NO, if produced from NO synthase during infection with $H$ pylori, may therefore counter the proapoptotic effects of this pathogen. (Gut 2000;46:156-163)

Keywords: nitric oxide; gastric mucosa; stomach; apoptosis
Extracts of Helicobacter pylori cause the expression of the inducible form of nitric oxide (NO) synthase (iNOS) in a macrophage cell line ${ }^{1}$ and in duodenal mucosal cells when injected intravenously into rats. ${ }^{2}$ Furthermore, patients infected with $H$ pylori exhibit iNOS activity in inflammatory cells in antral mucosa. ${ }^{3}$ The presence of nitrotyrosine in the mucosa of such patients, ${ }^{3}$ suggests that the NO synthase is active under these conditions, and that $\mathrm{NO}$ is being converted to peroxynitrite. However, perfusion of water soluble extracts of $H$ pylori through rat duodenum caused formation of the NOS inhibitor asymmetric dimethyl arginine. ${ }^{4}$ Formation of this agent from $\mathrm{H}$ pylori in human stomach in vivo might reduce iNOS activity. In normal subjects breakdown of nitrite in the gastric lumen generates NO. ${ }^{5}$ Thus in pathological and physiological circumstances gastric mucosal epithelial cells are likely to be exposed to exogenous $\mathrm{NO}$, although the extent of the exposure is currently unclear.

$\mathrm{NO}$ is also generated endogenously within gastric mucosal epithelial cells which have a considerable activity of the neuronal form of NOS. ${ }^{6-8}$ However, this enzyme is $\mathrm{Ca}^{2+}$ dependent, and under physiological circumstances is only likely to be transiently active, although it could become continuously so with persistent elevation of intracellular $\mathrm{Ca}^{2+}$ under pathological circumstances, when iNOS may also be present within epithelial cells. ${ }^{9}$

Sustained exposure of gastric mucosal cells to NO could induce apoptosis. Apoptosis is a cell death programme, which can be distinguished from necrosis by the condensation and fragmentation of nuclear material and by the specific cleavage of DNA between nucleosomes. ${ }^{10}$ In macrophages and several other cell types exogenous NO delivered from NO donors promoted apoptosis. ${ }^{11}$ However, not all cells show the same response to exogenous NO. Thus in human venous endothelial cells low concentrations of an NO donor inhibited apoptosis while higher concentrations promoted apoptosis. ${ }^{12}$ In bovine adrenal vascular endothelial cells, apoptosis in

Abbreviations used in this paper: iNOS, inducible nitric oxide synthase; NO, nitric oxide; ODQ,

1H-1,2,4-oxadiazole-4,3-a-quinoxaline-1-one; SNAP, S-nitroso-N-acetylpenicillamine; carboxy-PTIO, 2-(4-carboxyphenyl)-4,4,5,5-tetramethylimidazoline1-oxyl-3-oxide 
response to $\mathrm{NO}$ donors was promoted by the presence of a $\mathrm{Ca}^{2+}$ ionophore. ${ }^{13}$ In primary cultures of hepatocytes NO donors only inhibited apoptosis, ${ }^{14}$ and reduced the activation of proteolytic enzymes called caspases which play an important role in the apoptotic process. ${ }^{15} \mathrm{NO}$ raises cyclic GMP in cells by activating guanylate cyclase. The proapoptotic effects of NO do not seem to involve cyclic GMP but may in some instances be mediated by damage to the DNA and accumulation of $\mathrm{p} 53^{11}$ : antiapoptotic effects of $\mathrm{NO}$ can involve cyclic GMP. ${ }^{11}$

The primary cultures of guinea pig gastric mucosal cells used in this work have been found by Teshima and colleagues $^{16}$ to be constituted of $89 \%$ gastric epithelial cells, $1 \%$ mucous neck cells, and 4-5\% parietal cells, which supports our previous finding of at least $90 \%$ of the cells staining positively for mucus. ${ }^{17}$ In previous work, exposure to an $\mathrm{NO}$ donor induced expression of heat shock protein 72 after eight hours, and enhanced detachment of cells from the culture plate by 18 hours. ${ }^{17}$ The primary aim of the present work was to use this preparation to examine apoptotic responses of gastric mucous cells to long term exposure to exogenous NO, and to assess the involvement of cyclic GMP and caspases in any responses. If NO promoted apoptosis then this molecule could contribute to the apoptosis that is associated with infection with $\mathrm{H}$ pylori. ${ }^{3}{ }^{18} 19$ Alternatively, if NO inhibited apoptosis, then the production of $\mathrm{NO}$ on infection with $H$ pylori could have a defensive function.

Actions of NO donors on gastric mucous cells are also of interest because of the possible therapeutic use of NO donating non-steroidal anti-inflammatory drugs. Thus the addition of a NO donating nitroxybutyl moiety to nonsteroidal anti-inflammatory drugs generates agents with reduced gastric toxicity, but which suppress prostaglandin synthesis and inflammation to an extent comparable to the parent compound. ${ }^{20}$ Although the mechanism of the reduced gastric toxicity is not fully established, it is possible that release of NO into the gastric lumen may be involved.

\section{Materials and methods}

ANIMALS

Male Dunkin-Hartley guinea pigs of 200-300 g body weight were obtained from Charles River, Margate, Kent, UK, and were fed on SDS Economy guinea pig diet supplied by Lillico, Betchworth, Surrey, UK.

\section{MATERIALS}

RPMI 1640 medium, fetal calf serum, antibiotics, and amphotericin B were from Life Technologies, Paisley, UK. The NO scavenger 2-(4-carboxyphenyl)-4, 4, 5, 5-tetramethylimidazoline-1-oxyl-3-oxide (carboxy-PTIO), $\mathrm{N}$-hexanoyl-D-sphingosine $\left(\mathrm{C}_{6}\right.$-ceramide), and caspase substrates and inhibitors were obtained from Alexis, Nottingham, UK. Pronase E (70 000 PU units per g) was purchased from Merck, Lutterworth, UK. Reagents for the fragment end labelling of DNA were purchased from Calbiochem, Nottingham, UK. 8-(4- chlorophenylthio)guanosine-3',5'-cyclic monophosphate (8-pCPT-cGMP) was from Biolog, Bremen, Germany. The immunoassay kit for cyclic GMP was from Amersham-Pharmacia, Little Chalfont, UK. Other reagents were from Sigma, Poole, UK.

\section{ISOLATION AND CULTURE OF GASTRIC MUCOUS} CELLS

The method has been described in detail previously. ${ }^{17}$ Guinea pig gastric mucosa was minced, incubated with $45 \mathrm{ml}$ of RPMI 1640 containing $2 \mathrm{~g} / \mathrm{l}$ bovine serum albumin (isolation medium) and $0.5 \mathrm{mg} / \mathrm{ml}$ pronase for 20 minutes at $37^{\circ} \mathrm{C}$ with shaking at 140 cycles per minute, and then, after centrifugation, with 45 $\mathrm{ml}$ isolation medium containing $0.4 \mathrm{mg} / \mathrm{ml}$ of collagenase for 20 minutes. Cells were filtered through $150 \mu \mathrm{m}$ nylon mesh, and washed in culture medium (RPMI 1640 containing 10\% fetal calf serum, $100 \mathrm{U} / \mathrm{ml}$ penicillin, $100 \mu \mathrm{g} / \mathrm{ml}$ streptomycin, and $2.5 \mu \mathrm{g} / \mathrm{ml}$ amphotericin B). The yield was 60 (7) million gastric cells per guinea pig $(n=5)$, and 2 million cells were placed in each well of six well culture plates. Unattached cells were removed after 24 hours when the culture medium was renewed. The medium was changed again at 48 hours, at which time the experiments were initiated by the inclusion of agents in the culture medium. All measurements were made after a further 24 hours, at which time there were 1.2 (0.07) million gastric mucosal cells per well, of which 8 (1) $(n=4)$ were in suspension under control conditions. Cell viability (Trypan blue exclusion) and number were determined as described previously. ${ }^{17}$

\section{DETECTION OF APOPTOSIS BY STAINING WITH} HOECHST 33258

Plates were agitated gently and the culture medium together with cells in suspension was removed and subjected to centrifugation for 20 seconds at $12000 \mathrm{~g}$. Cells attached to the culture plate were removed by treatment with trypsin (0.5 g/l) and EDTA (0.2 g/1). Typsinisation was terminated by addition of culture medium and cells were centrifuged as above. Cells were resuspended in $4 \%$ (wt/vol) paraformaldehyde in $138 \mathrm{mM} \mathrm{NaCl}, 2.7 \mathrm{mM} \mathrm{KCl}$, and $10 \mathrm{mM}$ phosphate (PBS) for 10 minutes at room temperature, subjected to centrifugation at $12000 \mathrm{~g}$ for 10 seconds, resuspended in ethanol:water $(4: 1)$, and stored at $4^{\circ} \mathrm{C}$. Cells were transferred to glass slides by use of a Shandon cytocentrifuge (800 $g$ for five minutes); the slides were washed in PBS for five minutes, stained in PBS containing $8 \mu \mathrm{g} / \mathrm{ml}$ of Hoechst 33258 for 10 minutes, rinsed in water and mounted in $44 \mathrm{mM}$ citrate, $110 \mathrm{mM}$ sodium phosphate buffer ( $\mathrm{pH}$ 5.5) containing 50\% (vol/vol) glycerol. Slides were coded and then the proportion of apoptotic nuclei was determined by counting using a fluorescent microscope with apoptosis defined as the presence of two or more condensed bodies per nucleus. 

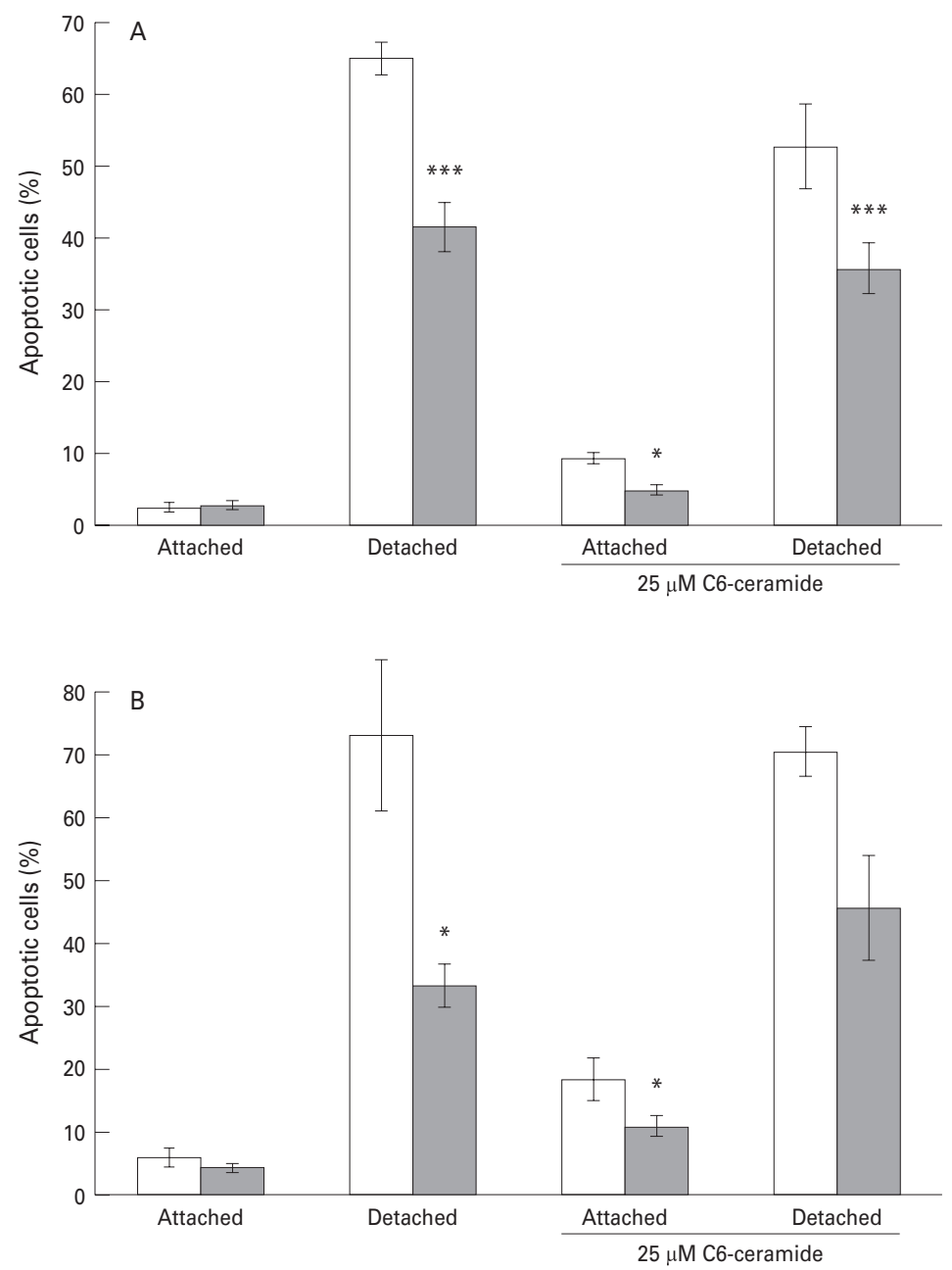

Figure 1 Effect of $1 \mathrm{mM} S$-nitroso-N-acetyl-penicillamine (SNAP; shaded bars) on apoptosis in guinea pig gastric mucosal cells in the presence and absence of $25 \mu \mathrm{M}$ $C_{6}$-ceramide. Apoptosis was detected by staining of nuclei with Hoechst 33258 in $A$ and by nick end labelling in $B$, with data presented as mean (SEM) of six and four separate cell preparations, respectively. Data were analysed by analysis of variance followed by a Newman-Keuls multiple comparison test. ${ }^{\star} p<0.05,{ }^{\star} \star \star x<0.001$ for the effect of SNAP in comparison with the same treatment without SNAP.

DETECTION OF APOPTOSIS USING FRAGMENT END LABELLING OF DNA

Cells on slides, prepared as above, were soaked in $20 \mathrm{mM}$ Tris, $140 \mathrm{mM} \mathrm{NaCl} \mathrm{pH} 7.6$ (TBS) for 15 minutes, permeabilised with proteinase $\mathrm{K}(20 \mu \mathrm{g} / \mathrm{ml})$ for five minutes, rinsed in TBS, and then exposed to $3 \%$ (vol/vol) hydrogen peroxide in methanol for five minutes. After preincubation with buffer $(200 \mathrm{mM}$ sodium cacodylate, $30 \mathrm{mM}$ Tris, $0.3 \mathrm{mg} / \mathrm{ml}$ bovine
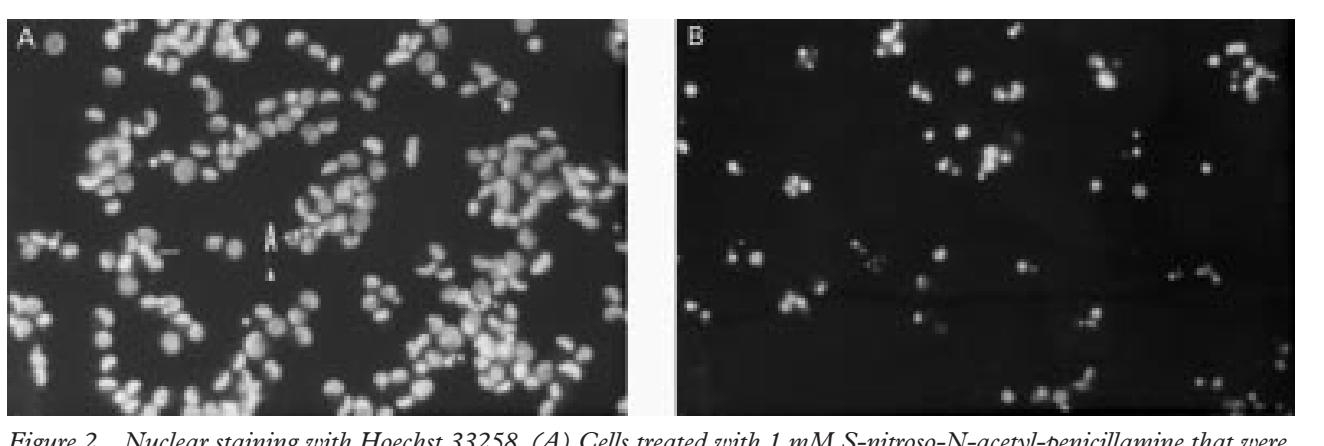

Figure 2 Nuclear staining with Hoechst 33258. (A) Cells treated with $1 \mathrm{mM} S$-nitroso-N-acetyl-penicillamine that were attached to the culture plate. One of the few apoptotic cells is labelled $A$. (B) Cells that had detached spontaneously under control conditions.

serum albumin, and $0.75 \mathrm{mM} \mathrm{CoCl}_{2}, \mathrm{pH} 6.6$ ) for 20 minutes, a reaction mixture containing biotinylated deoxynucleoside triphosphates and 15 units of 'Klenow' DNA polymerase was incubated with the slides at $37^{\circ} \mathrm{C}$ for 1.5 hours. The reaction was stopped with $0.5 \mathrm{M}$ EDTA $\mathrm{pH} 8.0$, the slide rinsed with TBS, blocked with $4 \%$ bovine serum album in PBS for 10 minutes and the presence of biotin detected by using a streptavidin-peroxidase conjugate and diaminobenzidine as substrate. Cells that stained dark brown were counted as positive.

\section{EXTRACTION AND DETECTION OF LOW}

MOLECULAR WEIGHT DNA

Cell pellets were resuspended in lysis buffer $(20$ $\mathrm{mM}$ Tris, $10 \mathrm{mM}$ EDTA, $0.5 \%$ (vol/vol) Triton $\mathrm{X} 100$ ) and left on ice for 30 minutes, after which the tubes were subjected to centrifugation at $13000 \mathrm{~g}$ for 30 minutes at $4^{\circ} \mathrm{C}$. The supernatants were extracted with phenol:chloroform:isoamyl alcohol (25:24:1) and then with chloroform:isoamyl alcohol (24:1). DNA was precipitated with 0.1 vol $3 \mathrm{M}$ sodium acetate and 2 vol ethanol and a pellet obtained by centrifugation at $16000 \mathrm{~g}$ for 15 minutes at $4^{\circ} \mathrm{C}$. Pellets were resuspended in $10 \mathrm{mM}$ Tris and $5 \mathrm{mM}$ EDTA pH 8.0 and incubated with $110 \mu \mathrm{g} / \mathrm{ml}$ of RNAse A at $37^{\circ} \mathrm{C}$ for one hour. Extracts were resolved on a $1.8 \%$ agarose gel and stained with ethidium bromide.

CASPASE ASSAY

The procedures adopted for preparation of homogenates, and for fluorimetric assay of caspases using the substrates Ac-Tyr-Val-AlaAsp-7-amido-4-methylcoumarin and Ac-AspGlu-Val-Asp-7-amido-4-methylcoumarin for caspase 1 and caspase 3 respectively were as described by Kim and colleagues ${ }^{15}$ for hepatocytes.

CYCLIC GMP

Cells were exposed to agents for four hours, the culture medium was removed, and cells on the plate were extracted with ice cold $65 \%$ ( $\mathrm{vol} / \mathrm{vol})$ ethanol. Extracts were centrifuged for five minutes at $10000 \mathrm{~g}$ and $4^{\circ} \mathrm{C}$ and dried under nitrogen at $60^{\circ} \mathrm{C}$. Cyclic GMP was determined by immunoassay (Amersham kit).

STATISTICAL ANALYSIS

Results are presented as mean (SEM), with $n$ equal to the number of cell preparations, and unless stated otherwise were subjected to 


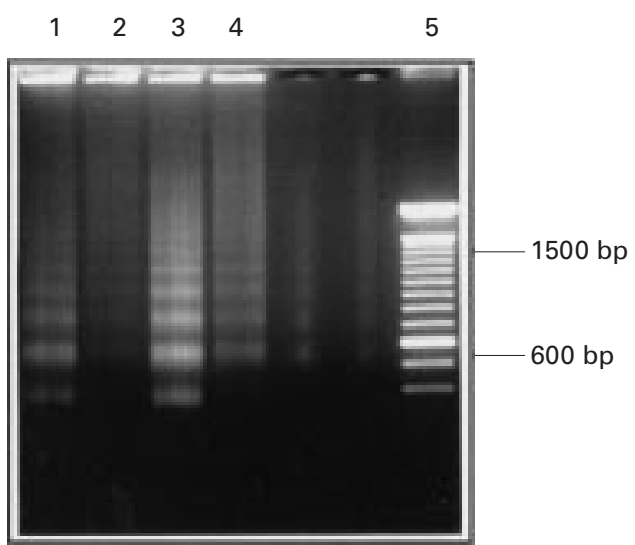

Figure 3 Fragmentation pattern of low molecular weight DNA as revealed by electrophoresis on agarose. Cells were treated with $25 \mu \mathrm{M} \mathrm{C}_{6}$-ceramide in the presence (lanes 2 and 4) and absence (lanes 1 and 3) of $1 \mathrm{mM}$ S-nitroso$N$-acetyl-penicillamine. Extracts from cells attached to the culture plate are in lanes 1 and 2 and cells that had detached are in lanes 3 and 4. Markers are in lane 5.

analysis of variance followed by either a Newman-Keuls or a Dunnett's multiple comparison test. Data on cell detachment were analysed before conversion to percentage of control, while data on apoptosis were arcsine transformed before analysis.

\section{Results}

APOPTOSIS UNDER CONTROL CONDITIONS AND THE EFFECT OF $\mathrm{C}_{6}$-CERAMIDE

Only a small proportion of cells attached to the culture plate were detected as apoptotic either by staining with Hoechst dye or by nick end labelling of DNA (fig 1). In cells which had
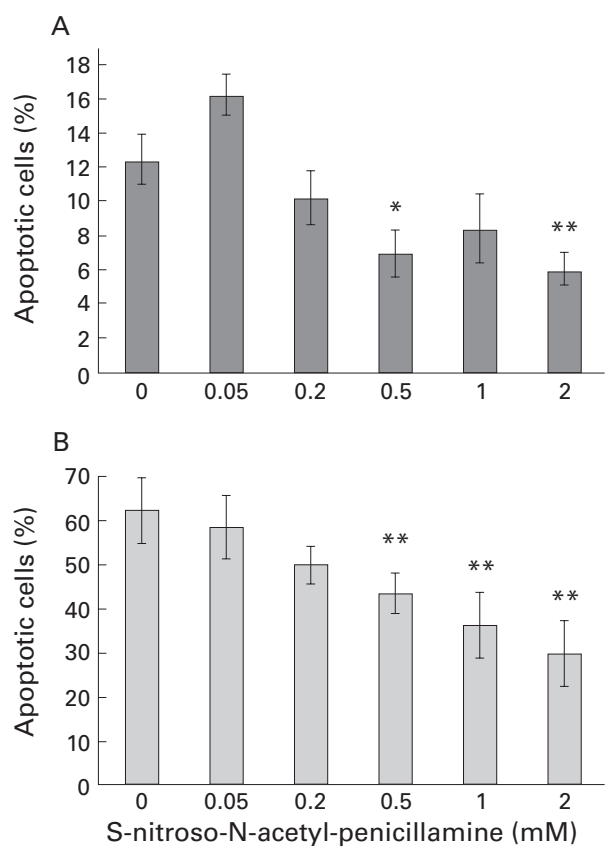

Figure 4 Effect of the concentration of $S$-nitroso-N-acetyl-penicillamine (SNAP) on apoptosis in cells attached $(A)$ and detached $(B)$ that had been treated with $25 \mu M C_{6}$-ceramide. Apoptosis was quantified by staining of nuclei with Hoechst dye. Data are the mean (SEM) of four separate cultures and have been analysed by analysis of variance followed by Dunnett's test. ${ }^{*} p<0.05$, ${ }^{\star *} p<0.01$ for comparison with the result obtained in the absence of SNAP. spontaneously detached from the culture plate, nuclear condensation and fragmentation was substantially increased $(p<0.001$ and $p<0.05$ by paired $t$ test for comparison with detached cells for Hoechst staining and nick end labelling, respectively; figs 1 and 2). The proportion of cells in suspension with apoptotic nuclei was significantly greater than those permeable to trypan blue (66 (2.4)\% apoptotic versus 28 (5.1)\% permeable to trypan blue, $\mathrm{p}<0.05$ by paired $t$ test, $\mathrm{n}=3$ ). Addition of $\mathrm{C}_{6}$-ceramide increased apoptosis in attached cells $(p<0.01$ for both Hoechst staining and nick end labelling; fig 1), but did not increase apoptosis in cells which had detached from the plate.

\section{EFFECT OF SNAP ON APOPTOSIS}

SNAP $1 \mathrm{mM}$ did not promote apoptosis in cells which were attached to the culture plate (figs 1 and 2). If cells were incubated with the calcium ionophore A23187 (200 nM) $1 \mathrm{mM}$ SNAP also had no effect on apoptosis in attached cells $(4.2(1.0) \%$ and $4.3(0.56) \%$ by Hoechst staining in the absence and presence of SNAP, respectively, $n=3$ ). If $\mathrm{C}_{6}$-ceramide was present, $1 \mathrm{mM}$ SNAP reduced apoptosis in cells attached to the culture plate by 49 (4)\%; in cells which had detached, SNAP reduced apoptosis by 31 (5)\% and 36 (3)\% in the presence and absence of ceramide (figs $1 \mathrm{~A}$ and 3 ; percentage values are for results with Hoechst staining in fig 1). This inhibitory effect of SNAP was dose related, being significant at 0.5 mM SNAP and still present at $2.0 \mathrm{mM}$ SNAP with 52 (3)\% inhibition for both attached and detached cells (fig 4).

EFFECT OF SNAP ON CASPASE ACTIVITY

Activity degrading the caspase 3 substrate Ac-Asp-Glu-Val-Asp-7-amido-4-methylcoumarin was detected in extracts from both attached and detached cells (fig 5), and was completely abolished $(n=3)$ by the caspase 3 inhibitor Ac-Asp-Glu-Val-Asp-CHO (100 $\mathrm{nM})$. Activity against the caspase 1 substrate Ac-Tyr-Val-Ala-Asp-7-amido-4-methylcoumarin, was $4.2(0.7) \%$ and $1.1(0.4) \%$ of that for the caspase 3 substrate for extracts from attached and detached cells, respectively $(\mathrm{n}=3)$. SNAP $(1 \mathrm{mM})$ reduced caspase 3 like activity by $88 \quad(4.8) \% \quad(\mathrm{p}<0.001)$ and 88 $(2.77) \%(\mathrm{p}<0.01)$ in detached cells in the presence and absence of $\mathrm{C}_{6}$-ceramide, respectively $(\mathrm{n}=5)$, and by $77(3.7) \%(\mathrm{p}<0.001)$ in attached cells incubated with $\mathrm{C}_{6}$-ceramide $(n=5)$ (fig 5).

EFFECT OF CARBOXY-PTIO ON APOPTOSIS

Carboxy-PTIO $1 \mathrm{mM}$ prevented the inhibitory effect of SNAP on apoptosis in cells that had detached from the culture plate (fig 6A). In the presence and absence of $25 \mu \mathrm{M} \mathrm{C}_{6}$-ceramide, apoptosis was increased by carboxy-PTIO in cells attached to the culture plate (fig 6B). This result invalidated the use of carboxy-PTIO to probe the action of SNAP on ceramide induced apoptosis because antagonism by SNAP of proapoptotic effects of ceramide and carboxy-PTIO could not be distinguished. 


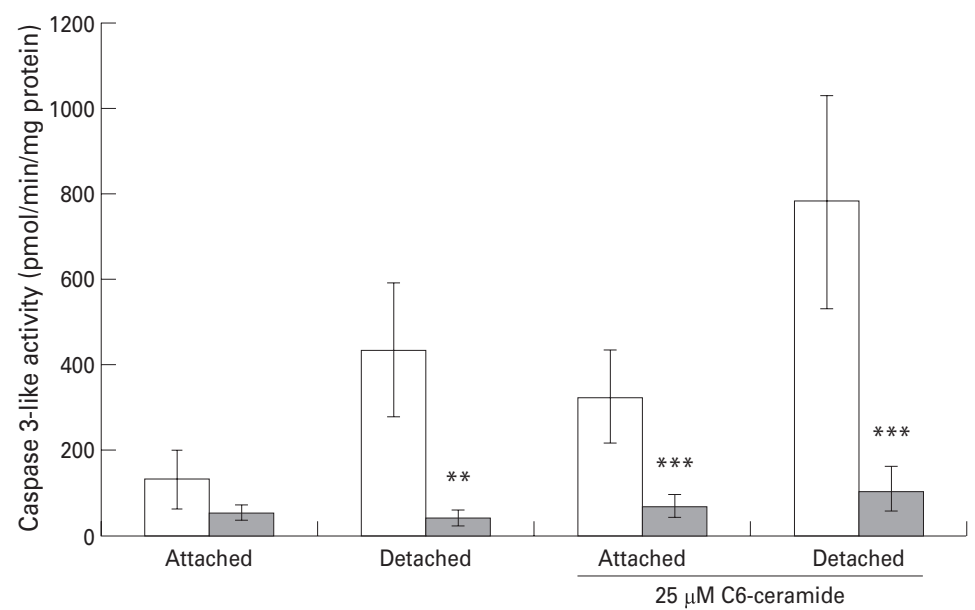

Figure 5 Effect of $1 \mathrm{mM}$ S-nitroso-N-acetyl-penicillamine (SNAP; shaded bars) on caspase 3 like activity in extracts of guinea pig gastric mucosal cells incubated for 24 hours in the presence and absence of $25 \mu M C_{6}$-ceramide. Data are presented as mean (SEM) of five separate cell preparations. Data were analysed by two factor analysis of variance, to remove the effect of variation in caspase activity between experiments, followed by a Newman-Keuls multiple comparison test. ${ }^{\star *} p<0.01,{ }^{\star \star *} p<0.001$ for the effect of SNAP in comparison with the same treatment without SNAP.

Furthermore, carboxy-PTIO (1 $\mathrm{mM})$ increased $(\mathrm{p}<0.02)$ detachment of cells from the culture plate by $127(16) \%(n=3)$, and its use to investigate the mechanism by which SNAP induced detachment was therefore also inappropriate.

EFFECT OF ODQ ON APOPTOSIS, CYCLIC GMP, AND CELL DETACHMENT

The guanylate cyclase inhibitor $1 \mathrm{H}-1,2,4$-oxadiazole-4,3-a-quinoxaline-1-one (ODQ) did
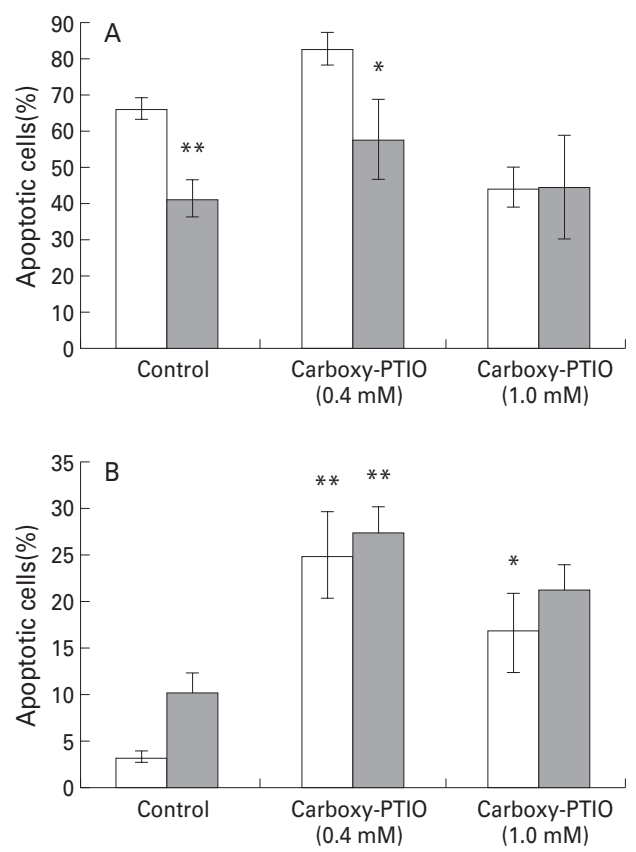

Figure 6 Effect of 2-(4-carboxyphenyl)-4,4,5,5-tetramethylimidazoline-1-oxyl-3-oxide (carboxy-PTIO) on apoptosis (Hoechst staining). (A) Data are mean (SEM) for cells which had detached from the plate in three separate experiments with the effect of $1 \mathrm{mM} S N A P$ (shaded bars) determined by paired t test; ${ }^{\star} p<0.05,{ }^{\star} p<0.01$. (B) Data are for attached cells in the presence (shaded bars) and absence (clear bars) of $25 \mu M C_{6}$-ceramide and are mean (SEM) of four separate cell preparations; ${ }^{\star} p<0.05$, ${ }^{\star} p<0.01$ for the difference from the appropriate control by a Newman-Keuls test. not alter the inhibitory effect of $1 \mathrm{mM}$ SNAP on apoptosis in attached cells induced by $\mathrm{C}_{6}$-ceramide or on the proportion of cells in suspension which were apoptotic in the absence of ceramide (fig 7A, B). However, ODQ completely prevented the stimulation of the cyclic GMP content of attached cells by SNAP (fig 7C), and partially inhibited the stimulation by the NO donor of the detachment of cells from the plate (fig 7D).

EFFECTS OF CYCLIC GMP ANALOGUES ON CELL DETACHMENT AND APOPTOSIS 8-Br-cGMP $1 \mathrm{mM}$ had no effect on detachment of cells from the culture plate (103 (15)\% of control, $n=4)$. 8-pCPT-cGMP, an analogue with high membrane permeability and phosphodiesterase stability also had no effect at concentrations of $0.1,0.3,0.7$, and $1.0 \mathrm{mM}$ (analysis of variance on data from three separate batches of cells) on the detachment of cells from the culture plate.

Neither 8-pCPT-cGMP $(0.1,0.3,0.7,1.0$ $\mathrm{mM}, \mathrm{n}=3)$ nor 8-Br-cyclic GMP $(0.1,0.3,1.0$ $\mathrm{mM}, \mathrm{n}=5$ ) significantly (analysis of variance) affected apoptosis induced by $\mathrm{C}_{6}$-ceramide (25 $\mu \mathrm{M})$ in attached cells. 8-Br-cyclic GMP (0.1, $0.3,1.0 \mathrm{mM}, \mathrm{n}=3$ ) did not affect apoptosis in detached cells incubated in the absence of $\mathrm{C}_{6}$-ceramide.

\section{Discussion}

The major finding of this investigation was that exogenous NO did not promote apoptosis under basal conditions in guinea pig gastric cells attached to the culture plate but rather inhibited the stimulatory effects of $\mathrm{C}_{6}-$ ceramide. For the cells in suspension the stimulation of apoptosis by detachment from the plate was inhibited by the NO donor. When counting cells in suspension very few large parietal cells were seen, and the previous work on the composition of the preparation ${ }^{1617}$ strongly suggests that observed effects were predominantly on mucous epithelial cells.

Identification of apoptotic nuclei by staining with Hoechst 33258 was based on key features of apoptosis, ${ }^{10}$ namely condensation and fragmentation of nuclear material. The Klenow fragment of DNA polymerase was used to label nicks in DNA as this enzyme is purported to give greater specificity for detecting apoptosis than the terminal deoxynucleotidyl transferase, ${ }^{21}$ and the results obtained showed a similar pattern to staining with Hoechst 33258. Finally, specific cleavage of DNA at sites between nucleosomes and the formation of a 'ladder' is a good, if rather qualitative, indicator of apoptosis and this procedure confirmed the inhibitory effects of NO shown with the staining procedures. Ceramide induces apoptosis by the activation of caspases and is a possible mediator of the apoptotic effects of tumour necrosis factor $\alpha,{ }^{22}$ which is increased in gastric mucosa infected with $H$ pylori. ${ }^{23}$ Little is known about how detachment promotes apoptosis but breakage of the matrix-integrin interaction may be the trigger. ${ }^{24}$ The concentration range of SNAP used, 50-2000 $\mu \mathrm{M}$, was sufficiently broad for both inhibitory and 

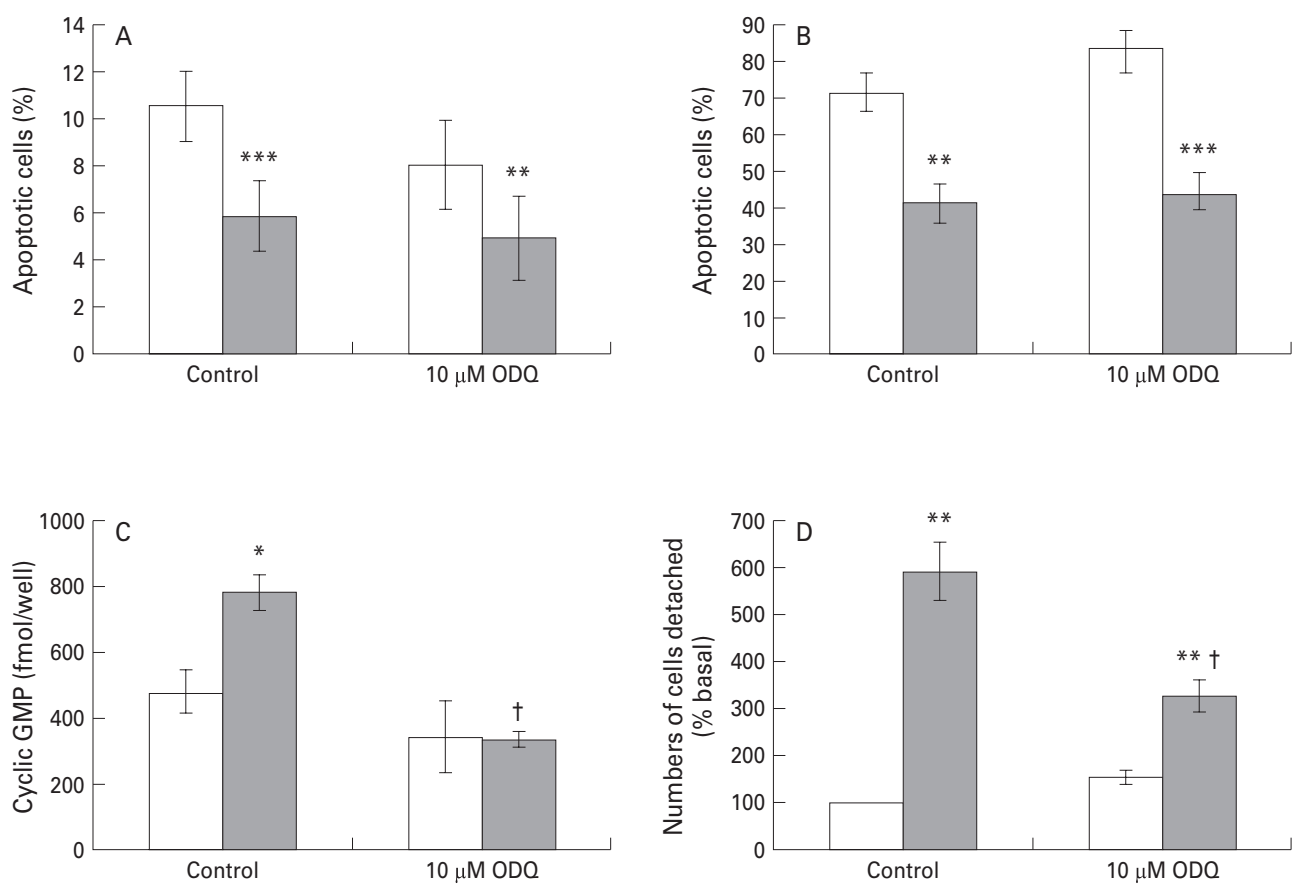

Figure 7 Effect of $O D Q(1 H-1,2,4-o x a d i a z o l e-4,3-a-q u i n o x a l i n e-1-o n e)$ on the action of $1 \mathrm{mM} S$-nitroso- $N$-acetylpenicillamine (SNAP, shaded bars) on apoptosis (Hoechst 33258 staining), cyclic GMP content, and on detachment of cells from the culture plate. The attached cells in panels $A$ and $C$ had been treated with $25 \mu M C_{6}$-ceramide to induce apoptosis. Results in $B$ are for detached cells. Data in A, B, C, and D are mean (SEM) of five, four, three, and three cell preparations, respectively, and were subjected to analysis of variance followed by a Newman-Keuls multiple comparison test. ${ }^{\star} p<0.05,{ }^{\star *} p<0.01,{ }^{\star \star} p<0.001$ for the effect of $S N A P ;+p<0.05$ for the effect of $O D Q$ in the presence of $S N A P$.

proapoptotic effects of SNAP to appear as judged by results with other cell types, ${ }^{12}$ and even if a calcium ionophore was added to raise intracellular $\mathrm{Ca}^{2+}$ no stimulatory effect of the NO donor was seen (compare this with results in Lopez-Collazo and colleagues ${ }^{13}$ ). Exogenous $\mathrm{NO}$ is therefore likely to inhibit apoptosis triggered by two different stimuli in gastric mucous cells.

Short term exposure of suspensions of rat gastric epithelial cells to NO donors causes damage, as exemplified by an increased proportion of cells being permeable to trypan blue, ${ }^{25}$ and in intestinal mucosal cells cyclic GMP appears to mediate such damage ${ }^{26}$ In the present work a deleterious effect of exogenous NO was to promote detachment of cells from the culture plate ${ }^{17}$ (fig 7). An involvement of cyclic GMP was suggested by the partial inhibitory effect of the guanylate cyclase inhibitor ODQ, which abolished the rise in cyclic GMP induced by SNAP. However, neither of the cyclic GMP analogues promoted cell detachment, and although elevation of cyclic GMP may therefore facilitate detachment of cells effected by NO, additional effects of NO/SNAP seem to be essential to initiate this detachment. If $\mathrm{NO}$ is released during chronic infection with $H$ pylori and promoted cell detachment it might contribute to the enhancement of cell turnover that is found in this condition. ${ }^{18}$

Prevention by the NO scavenger, carboxy-PTIO,${ }^{27}$ of the antiapoptotic effect of SNAP on suspended cells suggested that the action of SNAP was mediated via NO release. A similar use of carboxy-PTIO to investigate apoptosis induced by ceramide was precluded because carboxy-PTIO, by an unknown, possibly non-specific, mechanism increased apoptosis in response to ceramide. There was no evidence that the antiapoptotic effects of NO were mediated by cyclic GMP. Thus ODQ did not prevent the inhibitory effect of the NO donor on apoptosis due to $\mathrm{C}_{6}$-ceramide or to detachment from the culture plate, but ODQ abolished the elevation in cyclic GMP effected by SNAP. Secondly, analogues of cyclic GMP did not significantly reduce apoptosis in detached cells or attached cells exposed to ceramide.

Reasons that NO did not promote apoptosis may include the induction of heat shock proteins $^{14}{ }^{17}$ or antiapoptotic proteins such as $\mathrm{Bcl}-2,{ }^{28}$ or the absence of an NO activated caspase distinct from caspase $3 .^{29}$ The demonstration that gastric epithelial cells can produce superoxide $^{16}$ is of considerable significance and some of the NO could have been removed by reaction with superoxide. ${ }^{16}{ }^{30}$ Inhibitory effects of NO could be mediated by S-nitrosylation of caspases, such as caspase $3,{ }^{15}$ and indeed inhibition of caspase 3 like activity on exposure to SNAP in the present study was associated with an inhibition of apoptosis.

An agent, which when released transiently under physiological conditions promoted detachment, but which inhibited apoptosis would be a candidate regulator of the process of restitution where cells migrate to reestablish an intact epithelium after damage ${ }^{31}$ and an involvement of $\mathrm{NO}$ in restitution has been suggested. ${ }^{31}$ The results suggest that the NO donating moiety of NO releasing nonsteroidal anti-inflammatory drugs may exert an antiapoptotic effect on gastric mucous cells 
and indeed these agents have been reported to inhibit apoptosis in vascular endothelial cells and caspase activity in gastric mucosa. ${ }^{32}$ Endogenous NO may also inhibit apoptosis (for example, hepatocytes).$^{15}$ However, the mixture of cytokines required to induce expression of inducible NO synthase (iNOS) in guinea pig cells has not, to our knowledge, been established. Furthermore, a complicating factor is that one of the candidate cytokines, tumour necrosis factor $\alpha$, can itself activate both proapoptotic and antiapoptotic pathways. ${ }^{33}$ The effect of endogenous $\mathrm{NO}$ and of NO releasing non-steroidal anti-inflammatory drugs on apoptosis will be the subject of future work. Finally, the implication of the present work for inflamed gastric tissue in which iNOS is active, is that, as in the hepatocytes, ${ }^{14}{ }^{15} \mathrm{NO}$ may protect against apoptosis induced by inflammatory mediators.

This work was supported by funds from INTAS.

1 Wilson KT, Ramanujam KS, Mobley HLT, et al. Helicobacter pylori stimulates inducible nitric oxide synthase expression and activity in a murine macrophage cell line. Gastroenterology 1996;111:1524-33.

2 Lamarque D, Kiss J, Tankovic J, et al. Induction of nitric oxide synthase in vivo and cell injury in rat duodenal oxide synthase in vivo and cell injury in rat duodenal epithelium by a water soluble extract

3 Mannick EE, Bravo LE, Zarama G, et al. Inducible nitric oxide synthase, nitrotyrosine and apoptosis in Helicobacte pylori gastritis: effect of antibiotics and antioxidants. Cancer Res 1996;56:3238-43.

4 Fandriks L, Von Bothmer C, Johansson J, et al. Water extract of Helicobacter pylori inhibits duodenal mucosal alkaline secretion in anaesthetized rats. Gastroenterology 1997;113 1570-5.

5 McKnight GM, Smith LM, Drummond RS, et al. Chemical synthesis of nitric oxide in the stomach from dietary nitrate in humans. Gut 1997; 40:211-14.

6 Brown JF, Tepperman BL, Hanson PJ, et al. Differential distribution of nitric oxide synthase between cell fractions isolated from the rat gastric mucosa. Biochem Biophys Res Commun 1992;184:680-5.

7 Price KJ, Hanson PJ, Whittle BJR. Localisation of constitutive isoforms of nitric oxide synthase in the gastric glandutive isoforms of nitric oxide synthase in the gastric gland

8 Price K, Hanson PJ. Constitutive nitric oxide synthases in Price K, Hanson PJ. Constitutive nitric oxide synthases in
rat gastric mucosa: subcellular distribution, relative activity rat gastric mucosa: subcellular distribution, relative activity form compared with cerebellum. Digestion 1998;59:30813.

9 Brown JF, Tepperman BL, Hanson PJ, et al. Lipopolysaccharide induces $\mathrm{Ca}^{2+}$-independent nitric oxide synthase activity in rat gastric mucosal cells. Eur F Pharmacol 1994 292:111-14.

10 Cohen JJ. Apoptosis. Immunol Today 1993;14:126-30.

11 Brune B, von Knethen A, Sandau KB. Nitric oxide and its role in apoptosis. Eur 7 Pharmacol 1998:351:261 72 .

12 Shen YH, Wang Xl, Wilcken DEL. Nitric oxide induces and inhibits apoptosis through different pathways. FEBS Lett 1998;433:125-31.
13 Lopez-Collazo E, Mateo J, Miras-Portugal MT, et al. Requirement of nitric oxide and calcium mobilisation for Requirement of nitric oxide and calcium mobilisation for
the induction of apoptosis in adrenal vascular endothelial the induction of apoptosis in adren

14 Kim Y-M, de Vera M E, Watkins SC, et al. Nitric oxide protects cultured rat hepatocytes from tumour necrosis factor$\alpha$-induced apoptosis by inducing heat shock protein 70 expression. f Biol Chem 1997;272:1402-11.

15 Kim Y-M, Talanian RV, Billiar TR. Nitric oxide inhibits apoptosis by preventing increases in caspase-3-like activity via two distinct mechanisms. F Biol Chem 1997;272:3113848 .

16 Teshima S, Rokutan K, Nikawa T, et al. Guinea pig gastric mucosal cells produce abundant superoxide anion through an NADPH oxidase-like system. Gastroenterology 1998;115: 1186-96.

17 Byrne CR, Hanson PJ. Induction of heat shock protein 72 by a nitric oxide donor in guinea-pig gastric mucosal cells. Eur 7 Pharmacol 1998;353:117-22.

18 Moss SF, Calam J, Agarwal B, et al. Induction of gastric epithelial apoptosis by Helicobacter pylori. Gut 1996;38:498501.

19 Chen G, Sordillo EM, Ramey WG, et al. Apoptosis in gastric epithelial cells is induced by Helicobacter pylori and accompanied by increased expression of BAK. Biochem Biophys Res Coтmun 1997:239:626-32.

20 Wallace JL, Reuter B, Cicala C, et al. Novel nonsteroidal anti-inflammatory drug derivatives with markedly reduced ulcerogenic properties in the rat. Gastroenterology 1994;107: 173-9.

21 Fehsel K, Kroncke K-D, Kolb-Bachofen, V. Assays for detection of nitric oxide induced apoptosis. Methods Enzymol 1996;269:426-34

22 Kuo M-L, Chen C-W, Jee S-H, et al. Transforming growth factor $\beta 1$ attenuates ceramide-induced CPP32/Yama activation and apoptosis in human leukaemic HL 60 cells. Biochem f 1997;327:663-7.

23 Crabtree JE, Shallcross TM, Heatley RV, et al. Mucosal tumour necrosis factor alpha and interleukin- 6 in patients with Helicobacter pylori-associated gastritis. Gut 1991:32: 1473-7.

24 Frisch SM, Francis H. Disruption of epithelial cell-matrix interactions induces apoptosis. F Cell Biol 1994;124:61926.

25 Tripp MA, Tepperman BL. Role of calcium in nitric oxidemediated injury to rat gastric mucosal cells. Gastroenterology 1996;111:65-72.

26 Tepperman BL, Abrahamson TD, Soper BD. The role of cyclic guanylate monophosphate in nitric oxide-induced injury to rat small intestinal epithelial cells. F Pharm Exp Ther 1998;284:929-33.

27 Maeda H, Akaike T, Yoshida M, Suga M. Multiple functions of nitric oxide in pathophysiology and microbiologyanalysis by a new nitric oxide scavenger. 7 Leukocyte Biol 1994;56:588-92.

28 Genaro AM, Hortelano S, Alvarez A, et al. Splenic B-lymphocyte programmed cell death is prevented by nitric oxide release through mechanisms involving sustained Bcl-2 levels. F Clin Invest 1995;95:1884-90.

29 Messmer UK, Reimer DM, Brune B. Protease activation during nitric-oxide-induced apoptosis: comparison between poly(ADP-ribose) polymerase and

30 Sandau K, Pfeilschifter J, Brune B. The balance between nitric oxide and superoxide determines apototic and necrotic death of rat mesangial cells. F Immunol 1997;158: 4938-46.

31 Yanaka A, Muto H, Fukutomi H, et al. Role of nitric oxide in restitution of injured guinea pig gastric mucosa in vitro. Am F Physiol 1995;268:G933-42.

32 Fiorucci S, Antonelli E, Morelli O, et al. Prevention of gastric damage by NO-releasing aspirin (NCX-4016) is mediated by inhibition of ICE-like proteases in gastric mucosa and endothelial cells. Gastroenterology 1988;114:G0500.

33 Wallach D. Cell death induction by TNF: a matter of self control. Trends Biochem Sci 1997;22:107-9. 